\title{
MODERN ENTREPRENEURSHIP AS A FACTOR FOR SUCCESS IN THE OPERATION OF TOURISM ENTERPRISES
}

\author{
Kiril Postolov', Marija Magdinceva Sopova ${ }^{2}$, Lidija Pulevska Ivanovska ${ }^{3}$, Tanja \\ Angelkova Petkova ${ }^{4}$, Saso Josimovski ${ }^{5}$
}

\begin{abstract}
Working without limits, changes in consumer preferences, and contemporary processes of global integration have changed the traditional concept of conduct for business enterprises. The application of the modern concept of entrepreneurship in tourism enterprises provides conditions for increasing efficiency. A focus on innovative approaches for basic activities, and continued allocation of total resources represent the main features of modern entrepreneurship. Modern entrepreneurship is the process through which the entrepreneur and employees are devoted to the opportunities at hand. This changes the concept of what constitutes entrepreneurship. The main objective of this paper is to show how the modern concept of entrepreneurship is a main factor in efficient operation of business enterprises. In this respect, knowledge and intellectual capital represent critical resources in operating and implementing information and communication technology as a necessity in coordinating business processes among tourism enterprises. The applied part of this paper involves practical research to perceive the presence of entrepreneurship. The paper concludes with proposing a modern entrepreneurial model as a main factor for improving business operations. The specific results will be indicated in the sphere of representation of teamwork, introduction of changes, staff training, introduction of innovations, and level of tolerance.
\end{abstract}

JEL Classification Numbers: L26, DOI: http://dx.doi.org/10.12955/cbup.v4.735

Keyword: efficiency, innovation, knowledge, entrepreneurial model, work promotion.

\section{Introduction}

The accelerated technological development and the evident patronizing development of information and communication technology are the basis for globalization in every area and aspect in the conduct of business enterprises. Working in global conditions creates limitless opportunities for job creation and profits. In order for a firm to be an entrepreneurial enterprise, their business processes must be managed in an enterprising way, regardless of the size of the enterprise (Drucker, 2005, p. 122). Improving operations and increasing efficiency of work is a challenge for any enterprise. The use of information and communication technology is a necessity for coordinating business activities. Also a necessity for understanding change, the traditional concept of entrepreneurship indicates the means of how entrepreneurs should work. Entrepreneurship involves an opportunity to satisfy the needs of consumers and create a product that will do just that (Jones \& George, 2008, p. 79).

The development and introduction of modern entrepreneurship in the business operations of enterprises in the field of tourism involves constant introduction of new forms of conduct, encouraging teamwork, an entrepreneurial concept of corporate behavior, and highlighting the importance of human resources for the operation of enterprises. Regardless of the type of enterprise, continuous processes of development and improvement of human resources creates value for the competitiveness of the enterprise. The size and type of company are not a limiting factor in terms of applying the modern concept of entrepreneurship. The modern concept of entrepreneurship is associated with companies that are constantly prepared to recognize opportunities and have the potential and ability to use the obtained information.

\footnotetext{
${ }^{1}$ Kiril Postolov, Faculty of Economics- Skopje, University: SS. Cyril and Methodius, Skopje, Macedonia, kirilp@eccf.ukim.edu.mk

${ }^{2}$ Marija Magdinceva Sopova, Faculty of Tourism and Business Logistics, Stip, UGD, Stip, Macedonia, marija.magdinceva@ugd.edu.mk

${ }^{3}$ Lidija Pulevska Ivanovska, Faculty of Economics- Skopje, University: SS. Cyril and Methodius, Skopje, Macedonia, lidijap@eccf.ukim.edu.mk

${ }^{4}$ Tanja Angelkova Petkova, Faculty of Tourism and Business Logistics, Stip, UGD, Stip, Macedonia, tanja.angelkova@ugd.edu.mk

${ }^{5}$ Saso Josimovski, Faculty of Economics- Skopje, University: SS. Cyril and Methodius, Skopje, Macedonia, sasojos@eccf.ukim.edu.mk
} 


\section{Modern Tendencies in Development of Entrepreneurship}

The processes of globalization and integration require a new philosophy for the operation of enterprises in the field of tourism. For enterprises participating in the global market, the location of a business is no longer important, but rather how that business achieves efficiency. All enterprises, regardless of ownership, size, and financial capability, or type of business conduct, have begun to act entrepreneurial, applying the fundamental principles of entrepreneurial behavior and entrepreneur management. Modern entrepreneurship involves a focus on global business conditions, global innovation, entrepreneurial organizational culture, expressed flexibility, and innovative strategy in operations. This concept creates a new entrepreneur model. Modern entrepreneurship provides conditions for successful performance in the market, encouraging the competitiveness of enterprises and high efficiency. All companies should behave entrepreneurship as a precondition for successful participation in the global market (Tisen, Andrisen \& Depre, 2006, p. 109). Modern trends in business operations of enterprises are changing the concept of business conduct towards assembly and establishment of an organizational structure that is most appropriate in terms of global operations. In terms of global operations, this is usually applied to three types of work organizations: multinational, interregional, and global. The concept of modern entrepreneurship involves a situation in which companies apply new ways of business conduct, new ideas within enterprises, and entrepreneurial philosophy that covers the entire operations (Covin \& Miles, 1999, pp. 47-63).

The modern concept of entrepreneurship focuses on essential elements of the entrepreneurial process: recognizing the opportunity, searching for opportunity, and committing to realize the opportunity.

\section{The Modern Concept of Entrepreneurship among Enterprises in the Field of Tourism}

Technological changes, the rising importance of information, and human resources are the basis for understanding the changes and modus operandi of the modern entrepreneur in the 21 st century. The effect of information and communication technology in business operations includes identifying and understanding the economic factors that shape changes in order to create appropriate goods and services to increase income. New factors include the emergence of novel products and services, increasing value of time in global networking, and virtual operations. Tourism is a particular service sector that applies modern trends in operations. Dynamic developments, changes in all segments of operations, competition, and the demands of tourists in the tourism market are forcing firms in this sector to continuously update their knowledge. The need to introduce new services and products encourages the development of modern entrepreneurship in tourism, because it forces companies to consider the possibilities of expanding their offerings by introducing new products and services. Hence, many companies are responding to the rapidly changing technical requirements and consumer demand through entrepreneurial behavior (Antoncic \& Hisrich, 2004, pp. 518-550). Using modern models of corporate entrepreneurship, or entrepreneurship development strategies, are a way of gaining and retaining competitive advantage and improving the operations of enterprises in the tourism sector. Enterprises participating in creating tourist supply, and that also apply the entrepreneurial culture, have implemented innovative behavior and are constantly prepared to introduce changes in their organizational structure and thinking among owners, managers, and employees of the company.

The role of the entrepreneur today is very different to that previously. The dynamic aspect of the organization is the basis for identifying elements of the new paradigm. The basis for successful enterprises is creativity, antithesis, and unusualness. The role of the entrepreneur in modern enterprises today faces consumer needs and requirements in an environment that creates the possibility of designing features of innovative strategies with no previous organizational readiness. Successful companies use basic organizational capacities when using resources in innovative ways to reach goals that were once unreachable for them (Hamel, 2006).

Creative use of resources, discovery of new, changing goals, and continuous "rejuvenation" of the company with new, young human resources revitalizes the enterprise. Creativity involves the possession and application of skills for combining ideas in one respect, or creating unusual combinations of more ideas in another. Although companies that encourage creativity operate in a specific way, creativity by itself is not sufficient for the modern way of working and creating new 
values. As a result of the creativity necessary to produce useful products, services, or new methods of working, i.e., to apply innovations in business operations, innovative enterprises are characterized by their skill in directing creativity into useful results.

In terms of developing and introducing changes in the workplace, enterprises need to encourage and foster innovative strategy in their operations. Possession of creative employees alone is not sufficient for an enterprise to be creative. The modern concept of entrepreneurial enterprises in the tourism sector is the identification and development of the following elements: employee knowledge, information, quality products and services, sustainable approaches, and use of modern information and communication technologies. Modern entrepreneurship can be applied to those businesses in the tourism sector that support innovation and teamwork, and value the role of staff in supporting and developing concepts of the operations. The motive for entrepreneurship is founded in the need to identify existing and new sources of customer dissatisfaction and develop opportunities for their solution and removal (Ramachandran, 2003, pp. 21-38).

Rapid development of technology is fast creating competitive companies that promote products to become competitive enterprises and "win over" consumers.

\section{Providing Prerequisites for Applying Modern Concept of Entrepreneurship in the Enterprises in the Tourism Sector}

The tourism sector is a very dynamic market with high growth potential due to specific consumertourism needs. Therefore, companies need to constantly adjust their concept of business operations and entrepreneurial behavior. This means applying original business processes and adapting these to the challenges of globalization and economic integration. Each company needs to simultaneously run three important business processes to promote, expand, and innovate (Drucker, 2005, p. 82). The enterprises in the developmental stage are characterized by discovering new job opportunities, introducing innovative ways of meeting demands of tourists, using modern technology, and change in approaches to employees. In modern enterprises, the usual way to change operations involves assessing existing ways in all aspects. The basic condition for applying this concept is the existence of an innovative organizational culture.

The existence of organizational culture that encourages innovation provides certain conditions for applying this concept of modern entrepreneurship. Operational innovation refers to the improvement of business processes, such as, customer relations, relationships with staff, logistics, and similar processes. Management innovation is contained by introducing change management processes across the enterprise. The modern concept of entrepreneurship applies to those businesses from the tourism sector that support innovation, teamwork, and value the role of staff in supporting and implementing the development of operations. Volatility and unpredictability represent necessary conditions for innovation and creativity (Stacey, 1997, p. 18).

Existence of an innovative organizational culture in enterprises means accepting the new style of behavior for the entrepreneur, as follows:

- Focus on the results of business operations where the entrepreneur defines clear, transparent objectives, given the existence of multiple solutions to a problem;

- Focus on openness where entrepreneurs attempt to follow all changes in the environment and, where necessary, take immediate actions;

- Use positive feedback information, where the entrepreneur is empowered through a process of constructive feedback at all levels in the enterprise;

- Apply small internal control where entrepreneurs introduce a minimum level of organizational control through implementing written rules, procedures, and regulations;

- Accept prejudice where entrepreneurs always insist on objectivity in all aspects of operations;

- Tolerate impractical activities where the entrepreneur knows how to listen to all opinions, including those considered unimportant or funny, because sometimes innovative processes may arise from these; 
- Tolerate risk in business conduct where the entrepreneur encourages all employees to innovate in operations and where eventual failure of some transforms into ability to learn; and

- Tolerate conflicting situations where the entrepreneur encourages open discussion and expression of opinions from every employee in the firm.

Entrepreneurs must know the necessity of constantly innovating business processes and thus, enable increased productivity and profitability and ensure appropriate conditions for innovation. They must be directed towards major changes and innovate new principles. In an environment where new challenges dominate, it is the entrepreneur who needs to be inventive, untraditional, and sensitive to differing signs from an environment that is inventive and unconventional, with a necessity of terminating the traditional way of operating through introducing innovative ways, and understanding problems and their solution. The identity of companies that apply modern entrepreneurship varies according to five main elements: autonomy, innovation, proactivity, competitive aggressiveness, and taking risks (Dess, Ireland, Zahra, Floyd, Janney, \& Lane, 2003).

The concepts of modern entrepreneurship in companies specializing in the tourism sector are implemented by innovative employees. Entrepreneurs who understand the value of employees in developing the company in implementing the supply of tourists, apply the concept of modern entrepreneurship.

The application of modern enterprising approach in the operation of enterprises in the field of tourism depends on representation of the following concepts of work:

- Creating specialized, flexible work teams;

- Networking and coordination of teams with the help of information and communication technology;

- Reducing hierarchy and introducing democracy in business decision making;

- Increasing employees' autonomy and independence in decision making;

- Continuous investment in knowledge and education of employees;

- Continuous monitoring, assessment, and evaluation of intellectual capital;

- Building partnerships with customers and suppliers;

- Implementing continuous learning; and

- Encouraging innovation and creativity.

\section{Methodology and Research Results}

The research into modern entrepreneurship in enterprises in the field of tourism was undertaken by considering these concepts in the operations: representation of teamwork, introduction of changes, staff training, introduction of innovations, and level of tolerance. The study involved enterprises in the tourism sector of the Republic of Macedonia with practical research conducted in 58 companies from this sector during 2015. A questionnaire consisting of 15 questions was sent to 80 enterprises of the tourism sector in the country, with 58 responding to the questions.

The results suggest that entrepreneurs or management of enterprises need to implement certain changes in management processes in terms of team work for all employees in their enterprise and for tolerance in overcoming conflicting situations. Entrepreneurs of all enterprises subject to the survey said they do not communicate transparently about problems in working with employees to improve performance. In addition, they do not listen to employees when required. In terms of preference and practice they apply the rules and procedures for the business processes. In case of errors in the operation, tolerance is almost nonexistent, either in terms of cooperation between employees or with the work itself.

Most surveyed companies, i.e., $54 \%$ of those surveyed, have regular staff training activities, though the training related to actual work performed by the employees. In addition, the majority of enterprises introduced innovations in the business operations with minimum level of training for the staff operating the new business processes. The surveyed entrepreneurs did not practice frequent 
conversations with their employees, but did give feedback to staff on results of operations in specific periods, through regular reporting on business conduct.

\section{Conclusion}

In modern working conditions, the process of globalization requires changes in fundamental rules and principles within business operations. Businesses that wish to stay competitive in the global market must adapt to new conditions in an appropriate way. The tourism sector is a very dynamic market area with high growth potential due to specific customer characteristics. Improvement of business operations and increase in work efficiencies is a challenge for any enterprise. The basis of a successful enterprise is constant introduction of new methods and forms of conduct. The introduction and development of modern entrepreneurship in the operation of tourism enterprises are driven by these basics:

- Emerging demands, where there is continued growth of the desires and demands of customers, for whom modern entrepreneurs attempt to have adequate supply; and

- Enterprise objectives, where developing objective for an enterprise need to be based on innovative resources and inventive adaptation of existing processes.

Based on the results of the survey, to understand the representative situation in terms of modern entrepreneurship in enterprises in the field of tourism, it can be concluded that the majority of companies surveyed introduce innovations, new forms of work, and new business processes. However, this cannot be said for encouraging innovative entrepreneurial culture because most companies had no research features for an innovative entrepreneurial culture. Therefore, companies who wish for their operations to thrive in a modern model of entrepreneurship have an opportunity to change their concept of work, by introducing programs of continuous training and job management, new ways of organizing business, information, and communication systems, and new management processes, that will prepare them for modern entrepreneurship. The modern entrepreneurial model has a main factor of enhanced performance, and consists of developing:

- new products and services, where modern entrepreneurs constantly develop an appropriate portfolio of new products and services by regularly introducing innovations, new forms of work, and encouraging teamwork and entrepreneurial concept of corporate behavior; and

- professional capability, where contemporary entrepreneurs and staff are directed towards continuous learning and increased levels of personal knowledge, skills, and abilities, which in the future will create new values.

\section{References}

Antoncic, B., \& Hisrich, R. D. (2004). Corporate entrepreneurship contingencies and organizational wealth creation. Journal of Management Development. 23, 518-550.

Covin, J. G., \& Miles, M. P. (1999). Corporate entrepreneurship and pursuit of competitive advantage. Entrepreneurship: Theory and Practice. 23(3), 47-63.

Dess, G., Ireland, R., Zahra, S., Floyd, S., Janney, J. \& Lane, P. (2003). Emerging issues in corporate entrepreneurship. Journal of Management. 29.

Drucker, P. (2005). Management in the new society. Novi Sad: Adizes.

Hamel, G. (2006). Innovation. Harvard Business Review, February. 84(2).

Jones, G. R., \& George, J. M. (2008). Contemporary management. Texas: Rice University.

Ramachandran, K. (2003). Customer Dissatisfaction as a Source of Entrepreneurial Opportunity. Nanyang Business Review. 2(2), 21-38.

Stacey, R. (1997). Strategic management and organizational dynamics. Zagreb: Mate.

Tisen, R., Andrisen, D., \& Depre, F. I. (2006). Dividends of knowledge. Novi Sad: Adizes. 